\section{Within- and Between-family Variability for Important Bulb and Plant Traits among Sexually Derived Progenies of Garlic}

\author{
Maria M. Jenderek ${ }^{1}$ \\ Agricultural Research Service, U.S. Department of Agriculture, National Arid \\ Land Plant Genetic Resource Unit, Parlier, CA 93648
}

\author{
Yayeh Zewdie \\ Department of Biology, California State University, Fresno, CA 93740
}

Additional index words. Allium sativum, Allium longicuspis, breeding, clonal selection, garlic true seeds, phenotype, PI accessions

\begin{abstract}
Until recently, there has been no large-scale production of true seeds in garlic (A. sativum $\mathrm{L}$. and $A$. longicuspis $\mathrm{L}$.). The recent discovery of male fertile garlic accessions stimulated research on the genetics and breeding of garlic. However, there is no information regarding the phenotypic characteristics of garlic populations generated from true seeds. We evaluated the first generation of sexually derived families of garlic for bulb and clove weight, number of cloves per bulb, flower stalk height, number of leaves, plant height, and days required to achieve bulb maturity. Significant variations were observed within and among families for these important traits.
\end{abstract}

Due to its obligatory vegetative reproduction system, breeding in garlic has been exclusively done by the selection of clonal mutants. Lampasona et al. (2003) observed that since there is no segregating population generated from cross hybridization in garlic, it has not been possible to study stability and inheritance of phenotypic variation obtained through clonal selection. There are no studies in the literature on the use of sexual breeding methods in garlic (Simon and Jenderek, 2003). The recent discovery of male fertile garlic accessions from central Asia (Etoh, 1983, 1986; 1997; Hong and Etoh, 1996) and the ability to produce large quantities of true seeds (Etoh et al., 1988; Hong et al., 2000; Inaba et al., 1995; Jenderek, 1998; Pooler and Simon, 1994) opened an avenue for utilizing classical breeding methods and conducting genetic studies in this crop. The ability to produce true seeds is a breakthrough for the genetic improvement of garlic. Through sexual reproduction, it is possible to combine the desired traits from different clones into a single cultivar. Therefore, understanding the genetic structure of garlic populations derived from true seeds is essential for future breeding work.

Recently, Jenderek and Hannan (2004) reported the presence of variation in reproductive characteristics and seed producing potential for selected garlic accessions in the

Received for publication 3 Dec. 2004. Accepted for publication 31 Jan. 2005. We thank R. Hannan (USDA-ARS, Pullman, Wash.) and C. Ledbetter (USDA-ARS, Parlier, Calif.) for reviewing this manuscript before submission. Names are necessary to report factually on available data; however, the U.S. Department of Agriculture (USDA) neither guarantees nor warrants the standard of the product, and the use of the name by USDA implies no approval of the product to the exclusion of others that may also be suitable.

${ }^{1}$ To whom requests for reprints should be addressed; e-mailmjenderek@fresno.ars.usda.gov.
USDA collection. Jenderek (2004) reported on selected morphological characteristics among $S_{1}$ garlic progenies. However, to our knowledge, no other literature describes quantitative characteristics of bulbs and plants for populations generated from true seeds. The main objective of this study was to characterize the first generation of sexually derived garlic families for selected, economically important morphological characters.

\section{Materials and Methods}

Plant material. True seeds were produced from six garlic accessions that were obtained from the USDA germplasm collection maintained at the Western Regional Plant Introduction Station in Pullman, Wash. (Table 1).

In October 1999, 50 to 60 cloves from each accession were planted in the field at Parlier, Calif. At flowering stage, each accession was caged separately using insect-proofnet and blue bottle flies (Protophormia terraenovae Robineau-Devoidy) were used as pollen vectors. In August and September 2000, open-pollinated seeds were harvested from plants of each accession and bulked per accession. If all bulbs from one plant introduction (PI) traced back to a single plant, the seed harvested off asexual propagules (cloves) would be an $\mathrm{S}_{1}$ family. However if a PI traced back to more than one plant, the sexual seed from bulbs of this PI would represent a mass pollination among genetically diverse individuals. As a result, Unit, Parlier, Calif. we will refer to the seed from each accession as a sexually derived family. From November 2001 to February 2002, seeds of each sexually derived family were germinated in petri dishes. The germinated seeds were transferred to test tubes with half strength MS medium (M-5524; Sigma-Aldrich Co., St. Louis). At 2 to 3 leaf stage, the seedlings were transferred to plastic pots $(343 \mathrm{~mL})$ containing an artificial planting medium (Sunshine Mix No. 4; Sun Gro Horticulture Canada Ltd., Vancouver, Canada) and placed in a screenhouse. In February 2002, at three- to four-leaf stage, seedlings were transplanted to the field at $5 \mathrm{~cm}$ spacing between plants. Each plant was randomly numbered for evaluation purpose. Standard practices for growing garlic in California were used (Mann and Little, 1957). The first seed derived bulbs were harvested separately (per plant) in August 2002.

In Fall 2002, the seed derived cloves of each sexually derived family were planted back to the field with random cloves from their respective parental accessions. The experimental design was a randomized complete block design with four replications, with one plant in each replication. The bulbs were harvested in July to August 2003, and data of selected plant and bulb characteristics were taken from each plant.

In the 2003-04 growing season, the experiment was repeated for selected sexually derived progenies and a random sample of their maternal clones.

Data were collected for bulb weight (in grams); number of cloves per bulb; mean clove weight (in grams) (calculated by dividing the bulb weight by the number of cloves per bulb); flower stalk height in $\mathrm{cm}$ (measured from the base to the top of the flower umbel); number of leaves per plant (only in 2003); plant height in $\mathrm{cm}$ (measured from the plant base to the tip of the longest leaf; evaluated only in 2004); and days to physiological bulb maturity (the number of days from planting to $1 / 3$ leaves dry).

SPSS, version 11.5, software (SPSS, 2002) was used to analyze the data. ANOVA tables were calculated and means of the individual lines were compared to their respective maternal plant using Dunnett's $t$ test.

\section{Results and Discussion}

Relatively few sexually derived progenies were evaluated in each family and the number of surviving progenies varied due to the seed producing ability of the parental plants, low seed germination, poor seedling survival in vitro or poor survival in the field. Number of progenies evaluated in 2002-03 for maternal

Table 1. Garlic accessions used to develop sexual families at the National Arid Land Plant Genetic Resource

\begin{tabular}{llll}
\hline Seed family & Accession number & Allium species & Origin \\
\hline P2 & PI 540319 & A. sativum & Poland \\
P41 & PI 493099 & A. longicuspis & Moldova \\
P42 & PI 493116 & A. sativum & Czech Republic \\
P52 & PI 540356 & A. sativum & Georgia \\
P61 & PI 540316 & A. sativum & Former Soviet Union \\
P66 & PI 540315 & A. longicuspis & Former Soviet Union \\
\hline
\end{tabular}


accessions P2, P41, P52, P61, and P66 were $32,7,5,6,44$, and 4 , respectively (Table 2). Jenderek and Hannan (2004) previously reported significant differences in seed producing ability among individual plants within an accession and between accessions of garlic. Because garlic has been propagated asexually for centuries, it was assumed that mutations and deleterious characteristics were accumulated and maintained as heterozygotes in the genome. Following sexual reproduction, segregation for deleterious mutations would cause death or abnormalities of seedlings. Simon and Jenderek (2003) observed that seedling vigor and survival in garlic improves with progressing seed cycles as a result of selection against the deleterious aberrations.

In 2002-03, there was significant variation among the sexually derived families for bulb and clove weight, number of cloves per bulb, flower stalk height, number of leaves per plant, and days to maturity (Tables 2 and 3). Similarly within each family, significant differences were observed among individual plants for all characterstics, except for bulb weight and the number of leaves in family P66, and for number of leaves per plant in families P42 and P52. Individual plants within each family were significantly different from their respective maternal parent for the traits studied (ranges in Tables 2 and 3 ).

Bulb weight, number of cloves, and clove weight are the main factors contributing to garlic yield. Individual bulb and clove weight are of economic importance; medium or large bulbs with large cloves receive a higher price than a large bulb with small cloves (Zepeda and Laborde, 1997). In this study, bulb weight varied significantly within and among the sexually derived families. The smallest and largest average bulb weights were in families P42 (20 g) and P2 (38 g), respectively (Table $2)$. Within families, the smallest bulbs were observed in family P52 (6.0 g) and the largest in P2 (70.3 g) (Table 2). Similar differences were observed for number of cloves per bulb and clove weight. The lowest number of cloves per bulb was observed in P2 (5.3 cloves/bulb) and the largest number in P61 (40.3 cloves/bulb) (Table 2). The lowest clove weight was observed in the P61 family $(0.5 \mathrm{~g})$ and the largest in P41 family (7.7 g) (Table 2). Large bulbs with large cloves were observed in families P2 (70.3 and $6.4 \mathrm{~g}$, respectively) and P41 (61.9 and $7.3 \mathrm{~g}$, respectively).

Significant variations in flower stalk height and numbers of leaves per plant were observed among progenies within each family. The shortest flower stalk was observed in P61 $(40.5 \mathrm{~cm})$ and the longest in P2 $(140.5 \mathrm{~cm})$ (Table 3). Two sexual progenies in P52 and 16 progenies in $\mathrm{P} 61$ did not develop a flower stalk in 2003. The lowest number of leaves was observed in P2 (9.0/plant) while the largest in P41 (16.5/plant) (Table 3). The number of days to physiological bulb maturity varied within and between the families. The earliest plants were in P61 at $227 \mathrm{~d}$ (Table 3), i.e., 18 $\mathrm{d}$ earlier than the maternal parent. The latest plants were in P2 at $262 \mathrm{~d}$ (Table 3), i.e., 38 d longer than the maternal parent. Early and late maturing garlics may allow spreading of the harvest window.

In 2003-04, only selected families and progenies that had relatively large bulb size, low clove number/bulb, and large cloves were evaluated. Similar to the previous year, statistically significant variations were observed among the family means (Tables 4 and 5). Significant variations were also observed within each family, except for plant height in families P61 and P66, clove weight in families P2 and P61, bulb weight in family P66, and number of cloves in family P52 (data not presented). Individual plants within each family also were differed significantly from their respective maternal parent for all traits studied. Due to high temperatures during March and April 2004 in California, bulbs matured before reaching a commercially acceptable size and accounted for an average smaller bulb size than the 2002-03 growing season.

In conclusion, significant variations were observed for a number of traits studied within and among sexually derived garlic families in both growing seasons. Several progenies exhibited unique morphological characteristics not observed in their respective maternal parents for most traits studied, implying that vegetative propagation of garlic over the centuries has produced highly heterozygous plants. Sexual families generated from these plants could be an important source of unique phenotypes for garlic improvement.

Table 2. Means $( \pm \mathrm{SD})$ and range for bulb weight, number of cloves per bulb, clove weight among sexually derived families of garlic, evaluated in 2002-03.

\begin{tabular}{|c|c|c|c|c|c|c|c|}
\hline \multirow{2}{*}{$\begin{array}{l}\text { Seed } \\
\text { family }\end{array}$} & \multirow{2}{*}{$\begin{array}{c}\text { No. } \\
\text { of lines } \\
\text { evaluated }\end{array}$} & \multicolumn{2}{|c|}{ Bulb wt (g) } & \multicolumn{2}{|c|}{ Clove no. } & \multicolumn{2}{|c|}{ Clove wt (g) } \\
\hline & & Avg & Range & Avg & Range & Avg & Range \\
\hline$\overline{\mathrm{P} 2}$ & 32 & $38 \pm 18.9$ & $9.4-70.3$ & $9 \pm 3.4$ & $5.3-17.0$ & $4 \pm 1.8$ & $1.6-6.9$ \\
\hline P41 & 7 & $38 \pm 16.5$ & $22.2-61.9$ & $9 \pm 2.3$ & $6.0-12.3$ & $5 \pm 2.4$ & $2.5-7.7$ \\
\hline P42 & 5 & $20 \pm 12.6$ & $8.6-40.0$ & $10 \pm 1.7$ & $7.5-11.8$ & $2 \pm 1.0$ & $0.9-3.4$ \\
\hline P52 & 6 & $27 \pm 14.0$ & $6.0-47.9$ & $11 \pm 2.1$ & $7.5-13.5$ & $2 \pm 1.2$ & $0.8-3.3$ \\
\hline P61 & 44 & $24 \pm 7.2$ & $6.6-35.7$ & $17 \pm 8.9$ & $5.8-40.3$ & $2 \pm 1.0$ & $0.5-3.9$ \\
\hline P66 & 4 & $33 \pm 8.9$ & $26.5-37.9$ & $13 \pm 3.4$ & $9.3-15.8$ & $3 \pm 1.2$ & $1.7-3.7$ \\
\hline Significance $^{z}$ & & \multicolumn{2}{|c|}{0.01} & \multicolumn{2}{|c|}{0.01} & \multicolumn{2}{|c|}{0.01} \\
\hline
\end{tabular}

zProbability of significance level among the families based on an F test.

Table 3. Means $( \pm \mathrm{SD})$ and range for flower stalk height, number of leaves/plant, and days to maturity among sexually derived families of garlic, evaluated in 2002-03.

\begin{tabular}{|c|c|c|c|c|c|c|c|}
\hline \multirow{2}{*}{$\begin{array}{l}\text { Seed } \\
\text { family }\end{array}$} & \multirow{2}{*}{$\begin{array}{c}\text { No. of } \\
\text { lines } \\
\text { evaluated }\end{array}$} & \multicolumn{2}{|c|}{ Flower stalk ht $(\mathrm{cm})$} & \multicolumn{2}{|c|}{ No. of leaves } & \multicolumn{2}{|c|}{ Days to maturity } \\
\hline & & Avg & Range & Avg & Range & Avg & Range \\
\hline$\overline{\mathrm{P} 2}$ & 32 & $99 \pm 19.3$ & $70.8-140.5$ & $12 \pm 1.9$ & $9.0-17.0$ & $238 \pm 7.0$ & $231.0-262.0$ \\
\hline P41 & 7 & $101 \pm 19.3$ & $70.8-128.0$ & $13 \pm 2.5$ & $10.0-16.5$ & $245 \pm 5.2$ & $235.0-251.0$ \\
\hline P42 & 5 & $78 \pm 15.9$ & $55.5-99.0$ & $12 \pm 1.5$ & $10.5-12.8$ & $241 \pm 6.1$ & $231.0-249.0$ \\
\hline P52 & 6 & $66 \pm 12.1$ & $50.0-77.0$ & $12 \pm 1.8$ & $10.5-14.0$ & $246 \pm 7.5$ & $231.0-255.0$ \\
\hline P61 & 44 & $79 \pm 15.7$ & $40.5-100.0$ & $13 \pm 2.1$ & $10.3-15.8$ & $237 \pm 3.8$ & $227.0-248.0$ \\
\hline P66 & 4 & $102 \pm 9.7$ & $91.3-110.5$ & $11 \pm 1.3$ & $10.0-12.3$ & $244 \pm 5.2$ & $239.0-249.0$ \\
\hline \multicolumn{2}{|c|}{ Significance ${ }^{z}$} & \multicolumn{2}{|c|}{0.01} & \multicolumn{2}{|c|}{0.01} & \multicolumn{2}{|c|}{0.01} \\
\hline
\end{tabular}

${ }^{2}$ Probability of significance level among the families based on an F test.

Table 4. Means $( \pm \mathrm{SD})$ and range for bulb weight, number of cloves/bulb, clove weight among sexually derived families of garlic, evaluated in 2003-04.

\begin{tabular}{|c|c|c|c|c|c|c|c|}
\hline \multirow{2}{*}{$\begin{array}{l}\text { Seed } \\
\text { family }\end{array}$} & \multirow{2}{*}{$\begin{array}{c}\text { No. } \\
\text { of lines } \\
\text { evaluated }\end{array}$} & \multicolumn{2}{|c|}{ Bulb wt (g) } & \multicolumn{2}{|c|}{ Clove no. } & \multicolumn{2}{|c|}{ Clove wt (g) } \\
\hline & & Avg & Range & Avg & Range & Avg & Range \\
\hline $\mathrm{P} 2$ & 14 & $20 \pm 10.1$ & $9.0-40.1$ & $15 \pm 9.5$ & $5.3-36.8$ & $2 \pm 0.8$ & $0.9-2.8$ \\
\hline P52 & 2 & $22 \pm 11.6$ & $12.9-30.4$ & $10 \pm 8.6$ & $3.2-16.5$ & $4 \pm 3.6$ & $2.0-6.4$ \\
\hline P61 & 3 & $9 \pm 4.6$ & $5.2-11.4$ & $7 \pm 4.7$ & $2.8-10.0$ & $3 \pm 5.1$ & $0.8-7.9$ \\
\hline P66 & 2 & $13 \pm 6.5$ & $9.8-17.2$ & $12 \pm 2.4$ & $11.3-12.8$ & $1 \pm 0.4$ & $0.8-1.4$ \\
\hline Significance ${ }^{z}$ & & \multicolumn{2}{|c|}{0.01} & \multicolumn{2}{|c|}{0.03} & \multicolumn{2}{|c|}{0.01} \\
\hline
\end{tabular}

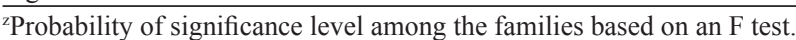

Table 5. Means $( \pm \mathrm{SD})$ and range for flower stalk height, plant height, and days to maturity among sexually derived families of garlic, evaluated in 2003-04.

\begin{tabular}{|c|c|c|c|c|c|c|c|}
\hline \multirow{2}{*}{$\begin{array}{l}\text { Seed } \\
\text { family }\end{array}$} & \multirow{2}{*}{$\begin{array}{c}\text { No. of } \\
\text { lines } \\
\text { evaluated }\end{array}$} & \multicolumn{2}{|c|}{ Flower stalk ht $(\mathrm{cm})$} & \multicolumn{2}{|c|}{ Plant ht $(\mathrm{cm})$} & \multicolumn{2}{|c|}{ Days to maturity } \\
\hline & & Avg & Range & Avg & Range & Avg & Range \\
\hline $\mathrm{P} 2$ & 14 & $80 \pm 18.9$ & $62.5-106.5$ & $61 \pm 11.5$ & $53.0-75.3$ & $183 \pm 9.7$ & $153.0-197.0$ \\
\hline P52 & 2 & $53 \pm 13.2$ & --- & $57 \pm 16.8$ & $42.3-70.8$ & $168 \pm 16$ & $153.0-183.0$ \\
\hline P61 & 3 & $\mathrm{NB}^{\mathrm{z}}$ & --- & $48 \pm 5.7$ & $46.0-50.3$ & $181 \pm 6.7$ & $176.0-190.0$ \\
\hline P66 & 2 & $81 \pm 10.1$ & $78.8-82.8$ & $63 \pm 13.7$ & $58.3-68.3$ & $190 \pm 7.4$ & $183.0-197.0$ \\
\hline \multicolumn{2}{|c|}{ Significance ${ }^{y}$} & 0.02 & & 0.01 & & 0.01 & \\
\hline
\end{tabular}

${ }^{\mathrm{z}} \mathrm{NB}=$ nonbolting.

y Probability of significance level among the families based on an F test. 


\section{Literature Cited}

Etoh, T. 1983. Germination of seeds obtained from a clone of garlic, Allium sativum L. Proc. Jpn. Acad. 59(Ser. B):83-87.

Etoh, T. 1986. Fertility of the garlic clones collected in Soviet Central Asia. J. Jpn. Soc. Hort. Sci. 55:312-319.

Etoh, T. 1997. True seeds in garlic. Acta Hort. 433:247-255.

Etoh, T., Y. Noma, Y. Nishitarumizu, and T. Wakamoto. 1988. Seed productivity and germinability of various garlic clones collected in Soviet Central Asia. Mem. Fac. Agr. Kagoshima Univ. 24:129-139.

Hong, C.J. and T. Etoh. 1996. Fertile clones of garlic (Allium sativum) abundant around the Tien Shan mountains. Breeding Sci. 46:349-353.

Hong, C.J., T. Etoh, and S. Iwai. 2000. An attempt of crossbreeding in garlic. Mem. Fac. Agr.
Kagoshima Univ. 36:17-28.

Inaba, A., T. Ujiie, and T. Etoh. 1995. Seed productivity and germinability of garlic (in Japanese). Breeding Sci. 45(Suppl. 2):310.

Jenderek. M.M. 1998. Generative reproduction of garlic (Allium sativum L.) [Rozmanazanie generatywne czosnku (Allium sativum L.)] (in Polish). Zeszyty Naukowe Akademii Rolniczej im. H. Kollataja w Krakowie 57:141-145.

Jenderek, M.M. 2004. Development of S, families in garlic. Acta Hort. 637:203-206.

Jenderek, M.M. and R.M. Hannan. 2004. Variation in reproductive characteristics and seed production in the USDA garlic germplasm collections. HortScience 39:485-488.

Lampasona, S.G., L. Martinez, and J.L. Burba. 2003. Genetic diversity among selected Argentinean garlic clones (Allium sativum L.) using AFLP (amplified fragment length polymorphism). Euphytica 132:115-119.
Mann, L.K. and T.M. Little. 1957. Growing garlic in California. Univ. Calif. Veg. Crops Ser. 89:1-10.

Pooler, M.R. and P.W. Simon. 1994. True seed production in garlic. Sexual Plant Reproduction 7:282-286.

Simon, P.W. and M.M. Jenderek. 2003. Flowering, seed production, and the genesis of garlic breeding. Plant Breeding Rev. 23:211-243.

SPSS Inc. 2002. SPSS for windows release 11.5. Chicago.

Zepeda, A.H. and J.A Laborde. 1997. Number of cloves per bulb: Selection criteria for garlic improvement. II. Results with "Taiwan" type, p. 271-277. In: J.L. Burba and C.R. Galmarini (eds.). Proceedings of the first international symposium on Edible Alliaceae, 14-18 Mar. 1994, Mendoza, Argentina. 